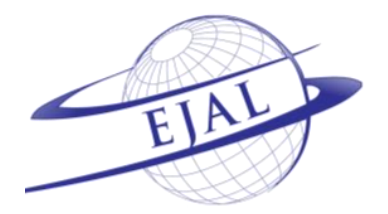

Available online at www.ejal.eu

\title{
New Beginnings: Trials and Triumphs of Newly Hired Teachers
}

\author{
Andrea Dimitroff a* (D), Ashley Dimitroff a + (D) \\ a TOBB University of Economics and Technology, 43 Söğ̈̈tözü Cd., Ankara 06510, Turkey \\ Received 20 July 2017 | Received in revised form 28 May 2018 | Accepted 24 July 2018
}

\begin{abstract}
APA Citation:
Dimitroff, A. \& Dimitroff, A. (2018). New beginnings: trials and triumphs of newly hired teachers. Eurasian Journal of Applied Linguistics, 4(2), 135-153. doi: 10.32601/ejal.464090
\end{abstract}

\begin{abstract}
Mitigation of challenges in a new workplace is one of the struggles encountered by newly hired teachers. This article presents the findings of a survey of various teachers in new work contexts. Most participants were surveyed after the completion of their TESOL MA or related master's programs, as well as undergraduate degrees and acquisition of teaching certificates. This qualitative data was gathered through the use of an online survey that included questions about participants' self-identified cultural backgrounds, teacher and/or educational training, work experiences, support networks, and adaptations in the workplace. As the data was analyzed, ideas of teacher identity and challenge mitigation were also explored. Findings include challenges faced by teachers, modes of adaptation, and practical tips for effectively adapting to the new work environment. The practical implications of this research include how teachers should strive to learn and adapt in each new context by relying on their teacher training and seeking assistance from sources of support in the new context.
\end{abstract}

(C) 2018 EJAL \& the Authors. Published by Eurasian Journal of Applied Linguistics (EJAL). This is an open-access article distributed under the terms and conditions of the Creative Commons Attribution license (CC BY-NC-ND) (http://creativecommons.org/licenses/by-nc-nd/4.0/).

Keywords: Workplace integration; training; adaptation; challenges; culture

\section{Introduction}

\subsection{English language teachers in transition}

Characteristically, English language teaching (ELT) is an intersection of the abilities of describing, categorizing, and understanding the world around oneself. The practice of teaching is considered to be ever changing and highly complex (LarsenFreeman, 2000). Succeeding in new contexts, such as new cultures or subcultures and educational settings is nothing new for individuals learning or teaching English as a foreign or second language. It is not surprising that English language teachers in new contexts experience countless challenges related to cultural adaptation, workplace integration, and effectiveness in the classroom.

\footnotetext{
* Corresponding author.

E-mail address: andreadimitroff14@gmail.com

†
} 


\subsection{The development of language teacher identity: The journey to teacher effectiveness}

It seems that at some point, every teacher is bound to ask themselves the critical question "Am I successful?" or "Is my teaching effective?". The answer to these questions influences the way they perform and apply theory into practice, which will in turn affect their workplace, their students, and the profession they represent. Therefore, the challenge facing teachers is how to be effective in each unique work context. This is especially true for new or newly qualified teachers (NQTs). As described by Farrell (2009), the first year of teaching "involves a balancing act between learning to teach.... and attempting to take on an identity as a 'real' teacher within an established school culture" (p. 183). Teacher identity is one of the formational components of Second Language Teacher Education (SLTE). Identity has been defined as a developmentally dynamic "process" of "the differing social and cultural roles [teachers in training] enact through their interactions with lecturers and other students during the process of learning" (Burns and Richards, 2009, p. 5). Development of teacher identity is specific to each person and each teaching situation. Leaders in the field of SLTE argue that challenge mitigation is an essential component of refining teacher identity. Common challenges that refine teacher identity include those that "conflict with [teacher] backgrounds, skills, social memberships, use of language, beliefs, values, knowledge, attitudes, and so on" (Miller, 2009).

Upon entering a new teaching context that includes challenges leading to identity formation, NQTs may find themselves searching for signs of effectiveness or success either in the classroom or in the workplace in general. Some would say that successful teachers are focused on student success (Maynes and Hatt, 2011, 2012), however, the definition of success can be difficult to determine. In fact, as Coombe (2013) states, researchers have not been able to come to an agreement about this question of teacher successfulness. In fact, some believe a consensus is not possible. As contended by Larsen-Freeman (as cited in Coombe, 2013, p. 3), what is perhaps easier to define and more integral to the educational process as a whole is not so much what is expected of teachers as to what they actually do in the classroom. Saafin and Sotto (as cited in Al-Mahrooqi, 2015, p. 2) state, the quality of teaching is most likely viewed through the lens of both teachers' and students' values. This implies that teaching success is different for each teaching context and will entail different feats for each teacher.

\subsection{Previous research related to cultural/contextual transition and adaptation}

Farrell reported his research on a novice teacher during the teacher's first year working in Singapore (2009). Common challenges observed in the teacher's first year were challenges related to teaching approach, curriculum, and relationships with colleagues. Challenges related to teaching approach and curriculum were attributed to the fact that the novice teacher's expectations of these areas were different from the 
reality he found in his new teaching context. The novice teacher's expectations were built on the training he had received in his teacher education program (Farrell, 2009).

The training teachers have received in teacher education programs has been numbered by Farrell as one of the "three major influences" that direct teachers as they complete their initial years of teaching (2009). In an effort to define the relationships between teacher educational degree level and student achievement, Brewer and Goldhaber (1996) conducted research on 24,000 high school students' performance on several nationwide tests. Teacher degree level was the main variable examined in relation to students' performance on the tests. Results of the study showed that there was generally no statistically significant impact of teacher degree level on student achievement. Despite this general conclusion, it was found that teachers' subject-specific degrees could possibly impact student achievement in areas such as maths and science.

In the same way that training influences teachers, novice teacher "socialization experiences" are another "major influence" on novice teachers given by Farrell (2009, p.182). By socialization, Farrell refers to how well the novice teacher adapts to the specific institutional culture and to the more general educational culture. Part of this socialization support should, ideally come from program administrators as well as the individual teachers. Not only is it important for teachers and administrators to foster and to seek out characteristics of effective teachers, it is also important that teachers and administrators establish what Villegas-Reimers (2003) referred to as continual sources of support to ensure continued teacher effectiveness. While it is true that teachers are responsible for developing effective characteristics within themselves, administrators are communicators of what roles teachers are expected to fulfill and are often identified as facilitators of change. The most effective progress can occur when teachers and administrators collaborate in mentor relationships that center on student success. The amplest time for this administrational mentorship is at the beginning of a teacher's career or placement within a position, before what some research claims is the "plateauing" of teacher effectiveness after three years of experience (Maynes and Hatt, 2013). Implications from research show that support is essential for novice and veteran teachers, but especially novice teachers in contexts that are new for them.

As well as having a supportive community at work, teachers need to develop individual forms of support, including self-support. Alfred Presbitero (2016) contended that, to decrease the negative effects of culture shock, people should acquire "cultural intelligence" or CQ. He defined this as "knowledge" or "understanding" of other cultures and worldviews that people should gain in order to appreciate cultural differences. Presbitero (2016) reported the "higher CQ" level a person has, the lesser he/she will be impacted by the negative effects of culture shock in terms of "psychological and sociological adaptation" (p. 30). A similar study exploring the correlation between U.S. college students' ideas of and dealings with culture shock was conducted by Goldstein and Keller (2015). The outcomes indicated that one's view of the self in relation to the foreign or new context can aid transition into a new 
culture. Gaw (2000) examined the problems encountered by American university students who were living in America for the first time in their lives. Gaw (2000) referred to the participants, who were children of overseas workers, as "returning sojourners" (p. 88), since they found themselves living in a culture that they were a part of, but was not the one in which they were raised. In an effort to "systematically examine" the emotional and social problems encountered by the participants, Gaw utilized a survey to question participants about specific challenges they faced in relation to the severity of the reverse culture shock that they experienced. Findings included the observation that participants' increased level of reverse culture shock contributed to participants' difficulties related to adaptation and emotional health in the new context.

There has been a variety of studies on cultural transition and adaptation as well as studies on teacher-identity development and teaching success. However, there appears to be a lack of studies specifically focusing on the comparison of English language teachers in new teaching contexts in the teachers' home countries and those working in new contexts in foreign countries. Examples of previous studies are the ones which focus on international students and language learners. The present study aims to investigate the role of teachers' educational background in the teachers' experience of and response to challenge in the new work context in home and foreign countries. Specifically, the question the researchers aim to answer in this study is:

Can field-specific education level have a positive effect on teachers' mitigation of professional, cultural, and personal challenges?

\section{Method}

A mixed method research design was employed through the use of an online survey. The survey included initial closed-ended multiple choice and rating-scale quantitative-based questions followed by open-ended short answer, qualitative-based questions. This was in order to collect both the statistics as well as the personal views related to the teachers' experiences, or as Creswell (2012) stated, the "numbers" as well as the "stories" related to the issue. While observing how the participants answered the initial, more quantitative-based questions about cultural stress, information was sought as to what solutions of or what modes of adaptation they utilized. This was done by analyzing participants' answers to the later open-ended, qualitative-based questions. In line with Creswell (2012) and Maynes and Hatt (2013), the researchers of this project held to the mindset that the participants are capable of providing valuable perspectives and ideas related to this topic. The authors of this study are aware of the fact that using a mixed method such as numerical data and participants' self-reporting have the potential to create various study limitations. These concerns, as well as further research suggestions are addressed in the limitations section. 


\subsection{Participants}

The participants were 37 teachers of English as a second or foreign language who are or were teaching in different contexts; the contexts varied in terms of country, institution type, and subject matter. The participants included persons of various age groups, educational backgrounds, and nationalities.

The participant-age ranges were: 18 to 24 years (2.63\% of participants), 25 to 34 (39.47\% of participants), 35 to 44 years (18.42\% of participants), 45 to 54 years (13.16\% of participants), 55 to 64 years (15.79\% of participants), and 65 to 74 years (10.53\% of participants). The gender of participants was recorded through a shortanswer section as a subdivision of the age question. Twenty participants reported themselves to be female, five reported as male, and twelve did not specify.

The majority of participants (53\%) reported that they had a Masters of Arts in TESOL, other master's degrees, and doctorate degrees. The second largest group of participants (43\%) had a CELTA, DELTA, or TEFL certificate. Only $3 \%$ of participants had an ELT bachelor's degree. Seven participants did not specify.

The majority of participants were from the United States (30 participants), 2 participants were from Iraq, 2 participants were from Saudi Arabia, 1 participant was from Japan, 1 participant was from Lithuania, and 1 participant was from Poland.

Concerning the question of participants' ELT field related experience, $37 \%$ of participants had no prior field-related work experience (prior to completing their highest ELT degree), $27 \%$ had 1 to 2 years of experience, and $36 \%$ had 3 or more years of experience.

The participants who had prior experience were asked in which country they worked during their initial year of teaching. Sixteen of these participants answered that they had taught their first year in a country identified their home country. Eleven answered that they worked in a foreign country.

\subsection{Data collection}

The tool used to collect data was a self-designed online survey which was sent to participants through both email and social media. As mentioned above, the survey consisted of closed-ended, multiple choice questions and open-ended, short answer questions. The survey consisted of three parts: personal information about the participants, information about the participants' new job or context, and finally, the participants' reflections on their own experience and advice for other teachers.

The participant information portion consisted of four demographic questions concerning participant age, gender, educational background, and country of origin. The section related to information about participants' new job or context consisted of three questions. The first of the questions was concerning the location of the new context--in the participants' country of origin or in a foreign country. The second question was a rating scale of level of severity of overall challenge faced--from 1 (not 
very challenging) to 5 (most challenging). Lastly, the third question required the participants to rank areas of challenge in order from 1 (least challenging) to 6 (most challenging). Areas of challenge that participants were asked to rank were: "culture/new language environment", "workplace routines/procedures", "co-workers", "students", "personal life" such as time commitments, homesickness, etc., and "other". The questions related to problem severity were similar to the questions used by Gaw (2000). Like Gaw's study (2000), the current study sought to "systematically" measure participants' social and emotional trials as they entered the new work context. The final section that was devoted to participants' reflections on their own experience and advice for other teachers was comprised of three questions. The first question in this section was an open-ended question that participants had to complete by describing how they mitigated challenges in the following areas: "culture/new language environment", "workplace routines/procedures", "co-workers", "students", "personal life" and "other". The next question asked participants to check the forms of emotional support they had during their experience in the new job or context. Options of emotional support were: "supportive bosses and/or co-workers", "a religious community", "friends from outside of work", "family", "none of the above", and "other". "Other" included a short answer section that was labeled "please specify". The final question of this section and of the survey was a short answer question querying participants' advice for "teachers entering new teaching positions".

\subsection{Data analysis}

The data gathered from the initial closed-ended questions was first descriptively analyzed by the online survey service Survey Monkey. Then, the researchers of this study conducted t-tests with XLMiner Analysis toolpak through Google Sheets to investigate the potential relationship between the participants' level of reported difficulty and both their level of field-related education and location of first year teaching. The data gathered from question eight, participants' descriptions of challenges they faced, and question ten, participants' advice for novice teachers, were analysed thematically by the researchers. Thematic analysis was used in order to observe and understand possible trends in the data set that could be informative in answering the research question of this present study. For this thematic analysis, the data was divided into groups; initially, question groups based on the participants' responses to questions eight and ten. Then those groups were further divided into two subgroups - field-related education groups (certificate holders or those who had completed a bachelor's degree (BA) or a more advanced degree), and finally, firstteaching-year-location groups (home country or foreign country). Each group of comments was analyzed and compared against one another to see what trends could be discovered in the data. Challenge mitigation roles of teachers which emerged from the analysis included: teachers as learners, teachers as assistance seekers, teachers as theoretical practitioners, and teachers as reflective advisors. 


\section{Results}

\subsection{Results from the initial survey questions (quantitative measures)}

As previously stated, the initial questions in the survey were closed-ended questions that were descriptively analyzed by the online-survey service and then analyzed by the researchers. This information from the initial questions was reported as follows.

\subsubsection{Level of challenges faced}

Participants' reported level of challenge was from not very challenging (1) to most challenging (5). Participants reported that they faced an average of 3.6 out of 5 .

\subsubsection{The rating of change (challenge) areas}

On a rating scale from 1 to 6 (where 1 equals least challenging), participants rated "workplace routines" as the most challenging at 4.71. "Co-workers" was rated the next most challenging at 4.18. "Students" was rated at 3.76, while "personal life" was rated at 3.64. Lastly "culture/new language" was rated at 3.4 and "other was rated at 3.0.

The researchers used information about challenges, education level, and first year location for the two t-tests (discussed below).

The first of the t-tests was conducted in order to investigate whether teaching in a foreign country was associated with level of reported difficulty of teaching during the first year. The sample of participants was divided into two groups; teachers who had completed their first year of teaching in a foreign country $(\mathrm{N}=11)$, and teachers who had completed their first year of teaching in their home country $(\mathrm{N}=16)$. For the home-country group, 2 participants didn't provide responses about the difficulty, making the actual group 14.

Table 1. Independent T-test Results Related to the Perceived Difficulty of First Year Teaching Between Teachers Who Have Taught in a Foreign Country and Those Who had Taught in their Home Country

\begin{tabular}{lllllllll}
\hline Groups & $\mathrm{N}$ & $\mathrm{x}$ & $\mathrm{sd}$ & $\mathrm{x} / \mathrm{x} 2$ & $\mathrm{df}$ & $\mathrm{t}$ & $\mathrm{p} *$ & $\mathrm{Significance}$ \\
\hline Home Country & 14 & 3.643 & 1.08 & \multirow{2}{*}{0.007} & 21 & 0.0146 & .9884 & n.s. \\
Foreign Country & 11 & 3.636 & 1.12 & & & & \\
\hline${ }^{*} \mathrm{p}<0.05$ & & & & & &
\end{tabular}

An independent-samples t-test was conducted to compare the teachers' reportedlevel of difficulty during their first year of teaching with the condition of being in their home country and the condition of being in a foreign country. In Table 1 below are summarized the descriptive statistics and the results of the t-test. There was not a significant difference in the scores for home country $(\mathrm{M}=3.643, \mathrm{SD}=1.17)$ and foreign country $(\mathrm{M}=3.636, \mathrm{SD}=1.25)$ conditions; $\mathrm{t}(21)=0.0146, \mathrm{p}=.9984$. The means of the two groups are nearly identical and the t-test show no significant difference in the level of reported difficulty $(\mathrm{p} .=.988)$. However, it should be highlighted that both groups of teachers rated their first year of teaching as quite difficult (according to the near 3.6 average on a 5 point difficulty scale). This shows that there does not seem to 
be a difference in the difficulty of teaching when comparing teaching in the home country or in a foreign one.

Also related to teachers' preparedness and confidence, is their achieved level of field-related education; this is the reason why the researchers were inclined to examine this variable in the research and decided to complete a second t-test. In order to discover whether level of education is associated with level of reported difficulty of teaching during the first year, the sample of participants was divided into two groups; teachers who had completed certificate programs $(\mathrm{N}=16)$, teachers who had completed bachelor's degrees $(\mathrm{N}=2)$, and also teachers who had completed master's or doctorate degrees $(\mathrm{N}=19)$. For the certificate group, 4 participants neglected to provide responses about the difficulty, making the actual group 14, in the other group, 1 participant from the bachelor's degree level didn't respond, making the actual number 1 (from the bachelor's level), and from the masters and doctorate degree level, 8 didn't respond, making the actual number 12 in the second group.

Similar to the above-mentioned t-test for location groups, an independent-samples t-test was conducted to compare the teachers' reported level of difficulty and the teachers' level of field-specific education level. In Table 2 below are the summarized descriptive statistics and the results of the t-test. There was not a significant difference in the scores for certificate holders $(\mathrm{M}=3.583, \mathrm{SD}=0.6685)$ and those with BA (or above) degrees $(\mathrm{M}=3.769, \mathrm{SD}=1.3634)$ conditions; $\mathrm{t}(17)=0.4379, \mathrm{p}=.667$. The means of the two groups are rather close and the t-test show no significance difference in the level of reported difficulty between the education level groups ( $\mathrm{p} .=.667)$. This demonstrates that there does not seem to be a difference in the difficulty of teaching when comparing field-related education level. However, it should be pointed out that both groups of teachers rated their first year of teaching as quite difficult (according to the near 3.6 average on a 5 point difficulty scale).

Table 2. Independent T-Test Results Related to the Perceived Difficulty of First Year Teaching in Relation to Field-Specific Education Level

\begin{tabular}{|c|c|c|c|c|c|c|c|c|}
\hline Groups & $\mathrm{N}$ & $\mathrm{x}$ & $\mathrm{sd}$ & $\mathrm{x} / \mathrm{x} 2$ & $\mathrm{df}$ & $\mathrm{t}$ & $\mathrm{p}^{*}$ & Significance \\
\hline Certificate & 12 & 3.583 & 0.6685 & \multirow{2}{*}{-0.6949} & \multirow{2}{*}{17} & \multirow{2}{*}{-0.4379} & \multirow{2}{*}{0.667} & \multirow{2}{*}{ n.s. } \\
\hline BA (or higher degree) & 13 & 3.769 & 1.3634 & & & & & \\
\hline
\end{tabular}

\subsubsection{Participants' networks/communities of support}

After considering the various challenges that the participants faced, the researchers inquired about how participants were supported. Participants rated forms of emotional support they had in their new job context. Participants rated "friends from outside of work" as $61.54 \%$, both "supportive boss and/or co-workers" and "family" as $57.69 \%$, "a religious community" as $23.06 \%$, "other" as $15.38 \%$, and "none of the above" as 3.8\%. Participants described "other" as families of their students and as their landlord and landlord's family. These items concluded the closed-ended items on the survey. 


\subsection{Results from the later open-ended survey questions (qualitative measures)}

As stated above, the data gathered from question eight, participants' descriptions of challenges they faced, and number ten, participants' advice for novice teachers, were analysed thematically by the researchers. After the comments were divided into the groups mentioned above, the researchers organized them into tables which are included in the Appendix. These responses were then analyzed and compared against one another to see what trends could be discovered in the data. Though the quantitative data discussed above showed no statistically significant difference between the perceived difficulty level of the two groups of teachers, the thematic analysis provided insights into possible differences between the two groups, as well as challenge mitigation roles which teachers assumed.

\subsubsection{Teachers as learners}

An analysis of participants' answers to question eight in the challenge categorized "language and culture" revealed that a common theme for all groups of participants was the priority of learning or entering each new situation as a "learner". One participant who had taught in a foreign country commented that he or she "tried to learn as much as possible". A notable difference between the participants was that participants who had taught in their home country described learning as "fun" whereas those who had taught in a foreign country discussed learning as seeming more stressful. Also in this challenge categorized as "language and culture", participants with a BA degree or higher commented about learning more detailed aspects of culture, such as "values", where certificate holders discussed communication in a more general sense.

\subsubsection{Teachers as assistance seekers}

The researchers of this study analyzed participants' descriptions of the challenge categories of "workplace routines" and "co-workers" collectively, due to the correlation participants seemed to make between these two areas. An analysis of participants' comments again exhibited the theme of learning. Another key word participants used was "ask". For instance, two participants with a BA degree or higher both stated they had "asked questions"; these two participants reported an identical response despite the fact that one of them was teaching in his or her home country and one was teaching in a foreign country. Participants with a BA degree or higher--regardless of working in their home country or not-- reported that they found themselves striving to follow expectations that had been defined by their superiors. This occurrence of teachers relying on co-workers for assistance, as well as striving to follow workplace routines highlights the importance of teacher "socialization experiences" during the first year (Farrell, 2009). Participants in each educational group had similar difficulties related to communication in both challenge areas of "workplace routines" and "co-workers". Regarding workplace routines, one certificate holding participant who had taught in a foreign country shared, "[workplace routines were] difficult, as communication (openness) about what was expected or how to do things was not 
always forthcoming”. Similarly, regarding co- workers, a BA or higher degree holding participant who worked in his or her home country reflected, "I didn't feel support from most co-workers, so I avoided them".

\subsubsection{Teachers as theoretical practitioners}

As for the challenge area of "students", the analysis revealed similarities between the two groups in both a strength and a weakness; both groups reported that they could rely on their training and were focused on learning about their students, however, both groups also stated that they sometimes struggled to apply their training (or knowledge) in real-life situations. Differences were seen between the two groups in the issues of student motivation and problems with students. Teachers teaching in their home countries seemed to report student motivation as lower and that there were more problems than did the foreign-country group. One participant in the home-group used the word "intimidating" to describe his or her first encounters with students. Another participant from the same group said that meeting the needs of students was "challenging" and that one of the most difficult tasks was "explaining" and "answering students' questions". One participant from the other group of teachers, teaching in a foreign country, reported that their students were "highly motivated" to learn. As for student problems, not much was reported by the foreigncountry group. Only a small difference could be seen as to field-specific training level and was between teachers in the home-group. Teachers in the BA and above group discussed using knowledge of teaching methods to meet student needs as well as gaining knowledge about students in order to teach more effectively. However, in the certificate group, the participants mainly discussed loving and/or enjoying the students. Though both of these outcomes are pleasant, it is interesting to observe the fact that the more advanced group referenced their knowledge over the interpersonal experience of the certificate-holding teacher.

\subsubsection{Teachers as reflective advisors}

As previously mentioned, the second question from which responses were taken and analyzed by the researchers was question ten (participants' advice for novice teachers). The commonalities that emerged in the data analysis, for all respondents, was a reliance upon training, the seeking of community and/or assistance, as well as a sense of learning both about one's self as well as new culture. In reference to training, the researchers encountered phrases such as "trust your training", "develop your theories", and "follow what you learned in training...". These phrases align with Farrell's claim that a teacher's previous training is a "mediating influence" during times in new contexts (2009). Concerning support and assistance, participants made several mentions of words like "ask questions", "support", and "mentor teacher[s]". Finally, the researchers observed the participants' necessity of learning. Participants advised other teachers to be "flexible", "not to give up", and to "hold success loosely". Participants' advice to be "flexible" and to have endurance mirror Burns and Richard's views that teacher identity is a lengthy and multifaceted "process" (2009). Participants also encouraged others to be learners - to "learn as much as you can", 
both about students and culture. The analysis of question ten clarified the concept that the participants viewed learning from themselves and new cultural situations as highly beneficial.

While these were the common themes seen throughout the analysis of question ten, a few differences were seen between the two level-of-training groups. As compared to the certificate-holders, the participants with BA degrees or above seemed more focused on specific needs, like visas and other legal requirements, seemed to give more detailed advice, and seemed to encourage others to stay or not to give up easily.

\section{Discussion}

By examining the answers to the initial questions and thematically analyzing the participant views represented in the short-answer questions, researchers were able to propose certain interpretations regarding the data.

Participants were varied in terms of age and gender, education background/training, home country, ELT related experience, and location of first year teaching. Although only $44 \%$ of participants experienced a new job context outside of their home culture (see Table 1), participants reported that changes were faced in both the home culture and the new culture; challenges were not dependent on the cultural context, but rather on the familiarity of the context and accompanying forms of support.

This was further evidenced by the conducted t-tests represented Tables 1 and 2. In Table 1, there was no statistically significant difference between the two location groups. However, both groups reported rather high levels of difficulty during that first year. The same phenomenon is presented in Table 2; there seems to be no statistical difference between the two field-specific education level groups. Only a high rating of difficulty is observed. These results are similar to those reported by Brewer and Goldhaber (1996). Although their study failed to find statistical significance in the relationship of teacher degree level and student achievement, they were able to relate some meaningful insights about the impact of specific "teacher characteristics" on learner achievement. The authors of the current research also argue that the conclusions gained from the thematic analysis of the given participant responses yield useful information about challenge mitigation strategies, which were used by participants; participants with a BA or higher degree seemed more focused on specific needs, seemed to give more detailed advice, and seemed to encourage others more than those with just certificates as previously stated.

From the participant information and reflections of time in the new job context, it is seen that challenge is a common experience of teachers; in new contexts, various challenges are expected. As seen in the Level of challenges faced, all participants reported some level of challenge. The level of challenge was varied and ranged from "not very challenging" (1) to "most challenging" (5), with a mean rating of 3.6 out of 5 . Just as the level of challenge participants faced varied, so did the forms of challenge. From the information presented in The Rating of Change (Challenge) Areas (section 
3.1.3), participants rated "workplace routines" as the area of greatest challenge, followed by "co-workers" and students". Job-related challenges were considered more challenging than personal/cultural challenges. This is perhaps because the participants probably spent more time and energy in the job context as opposed to the personal context.

Along with a variation in challenges faced was a variation in participants' response to challenges. As indicated in Participants' networks/communities of support , participants' primary form of support was "friends from outside of work". Perhaps this was the main form of support because "friends from outside of work" may have provided participants with a type of sabbatical from the work culture; having friends from outside of work could enable one to focus on his/her personal life by building a personal support network independent from job-related performance or relationships. Also, building support in this way could aid a person in establishing a sense of normalcy that he/she lost by leaving the familiar work and living context. As some of the participants referenced, communicating often with friends and family back home and also spending time with other expatriates was another means of support. A similar explanation can be used for the support system of a "religious community" that participants rated at $23.06 \%$. Perhaps belonging to a religious community helped bring a sense of normalcy and support to participants in a personal as opposed to a professional sense. This was the case for one participant who said that he felt he "had a home" in the religious community with others who didn't feel like they fit into the dominant culture. Interestingly, participants rated emotional support from "supportive boss/co-workers" and "family" equally at 57.69\%. One explanation for an equal rating of these support forms could be that participants viewed their workplace community as "family" or unit that could support them as they were far from their own family and friends. Again, the workplace could also be considered such an important form of support because participants probably spent such a great amount of time in the workplace context. There may also exist a sense of obligation or indebtedness to the company because the company may be responsible for the work and residency permits that allow teachers to live in the new country. This attitude is reflected in various participant quotes that discuss visa status as well as having good rapport with supervisors or others who are "responsible" for newly hired teachers. Besides the identified mitigation mechanisms the researchers listed in the survey, participants were also asked an open-ended question about mitigation methods.

Many participants stated in their responses that they made it a priority to make time for learning more language and culture. This challenge mitigation strategy of embracing the culture highlights the existence of participants' "cultural intelligence" as defined by Presbitero (2016). Participants' cultural intelligence could be attributed to their educational experience and was reported by some of the participants as a mindset through which to view themselves as they entered the new context. As noted by Goldstein and Keller concerning student-participants in cross cultural situations, the participants who had greater cultural awareness seemed to have a greater awareness of their "inward" cultural struggle, as well as individual ways to ease that 
struggle (2015). Participants also emphasized having patience with the adjustment process as well as themselves. Co-workers and friends were sources of cultural knowledge for many of the participants. All of these mitigation mechanisms appear to have also been used as part of the participants' processes of "establishing routines" and finding a new sense of normalcy. As mentioned above, participants had diverse backgrounds. Participants noted that they tended to depend on their previous training and teaching experience as they faced challenges in the new job context. In the other areas of culture and support, participants highlighted the importance of being a "continual learner" of culture and language, as well as trying to maintain open communication with bosses, supervisors, and co-workers.

\section{Conclusions}

\subsection{Possible implications}

The present study aimed to investigate the role of teacher education level and firstyear placement location in the teachers' experience of and response to challenge in the new work context. The analysis indicated that of the participants, most experienced similar challenges and employed various forms of mitigation mechanisms. Education and first year location were shown to have no statistically significant relationship to level of difficulty experienced. However, thematic analysis of responses to open-ended questions yielded useful information about challenge mitigation strategies which were used by participants. More field-specific training appeared to make individuals better equipped to mitigate challenges. This may suggest that teachers should complete field-related degree programs in order to be able to mitigate various challenges effectively.

One direct implication for teachers in new contexts is that they should assume the challenge mitigation roles given in Results from the later open-ended survey questions. Teachers must position themselves as "learners" in the new work context; learning school routines and procedures, students' expectations of the teacher, as well as co-workers' expectations of the new teacher were seen to be strategies which facilitated participants' integration. Furthermore, teachers should strive to apply theoretical training they have received into specific practices in the new context. Upon performing this application of theory into practice, teachers can develop themselves as theoretical practitioners who not only encounter, but also refine accepted ideas about language teaching and learning.

As teachers assume the above mentioned roles, those who are responsible for teachers (i.e. bosses, administrators, supervisors, and co-workers.), should scaffold the teachers. For example, those responsible for new teachers must remain available and approachable as teachers seek assistance. Professionals in the new teaching context should foster supportive environments for new teachers, as mentioned by VillegasReimers (2003). 


\subsection{Survey limitations}

This survey was limited possibly due to its mixed-method (partial open-response) design, its number of participants and its duration period. While the mixed method design allowed the researchers a wide glimpse into the participants' views, other methods, such as replacing the closed ended questions with personal interviews or all open-ended survey questions could have given the researchers further understanding of the participants' views. While the survey questions provided rich and informative data, some of the items could have been more clearly defined. Some of the closedended questions seemed to have possibly contained aspects of ambiguity, such as order of ranking. Another such possibly ambiguous question was the question about education level. A time frame of when the highest degree was completed and the first year of teaching could have provided more reliable data. This limitation stems partially from the fact that the data analysis was completed ad hoc. In the future, the researchers plan to design surveys in a less exploratory way, with more defined measures and possible outcomes in mind.

Concerning participant number, a larger participant pool might have yielded results that would be varied to some degree from the results of this study. Also, stronger evidence for the results yielded in this study could have been gathered. Increasing the duration of this study also could possibly have also been a variant in results gathered or support for the current, gathered results. Therefore, future recommendations to reformat this study into a longitudinal study that tracks preservice teachers before graduation, in their first year of teaching, and beyond into later years is offered. Many aspects such as the discussed stressors, contexts, and/or mitigation strategies could be examined individually and researched in more detailed ways. Due to the varied nature of this experiment, naturally, there were some confounding factors, such as teacher personality, the culture in which the teacher was teaching, the type of educational institution in which the teacher was teaching, and possible others. In the future, the researchers may narrow such aspects of the study in order to eliminate such confounding factors.

\section{Acknowledgements}

The authors would especially like to thank Dr. Krassimira D. Charkova and Dr. Aliel Cunningham for their guidance and input related to this study. The authors also thank the many anonymous individuals for their inspiration of and suggestions for the study.

\section{References}

Al-Mahrooqi, R., Denman, C., Al-Siyabi, J. \& Al-Maamari, F. (2015). Characteristics of a good EFL teacher: omani EFL teacher and student perspectives. SAGE Open, 5, 1-15. http://journals.sagepub.com/doi/pdf/10.1177/2158244015584782

Brewer, D.J., Goldhaber, D.D. (1996). Evaluating the effect of teacher degree level on education performance. Developments in School Finance, 197-210. Available from http://citeseerx.ist.psu.edu/viewdoc/download?doi=10.1.1.574.8129\&rep=rep1\&type=pdf 
Burns, A., \& Richards, J. (2009). Introduction. In A. Burns \& J. Richards (Eds.), Second language teacher education (pp. 1-8). New York, NY: Cambridge University Press.

Coombe, C. (2013). 10 Characteristics of Highly Effective EF/SL Teachers. Society of Pakistan English Language Teachers: Quarterly Journal, 28(4), 2-11. Available from https://zakiasarwar.files.wordpress.com/2015/05/6-vol-28-no-4-10-characteristics-of-highlyeffective-ef-sl-teachers-dr-christine-coombe-11.pdf

Creswell, J.W. (2012). Educational research: planning, conducting, and evaluating quantitative and qualitative research. Available from http://basu.nahad.ir/uploads/creswell.pdf

Farrell, T. S. C. (2009). The novice teacher experience. In A. Burns \& J. Richards (Eds.), Second language teacher education. (pp. 182-189). New York, NY: Cambridge University Press.

Gaw, K. F. (2000). Reverse Culture Shock in students returning from overseas. Journal of Intercultural Relations, 24, 83-104.

Goldstein, S. B., \& Keller, S. R. (2015). U.S. College students' lay theories of culture shock. Journal of Intercultural Relations, 47, 187-194.

Maynes, N., \& Hatt, B. E. (2011). Grounding program change in students' learning: A model for the conceptual shift in thinking that will support valuable program change in response to faculty of education reviews. In T. Falkenberg \& H. Smits (Eds.), The question of evidence in research in teacher education in the context of teacher education program review in Canada (2 vols.). Winnipeg: University of Manitoba, Faculty of Education.

Maynes, N., \& Hatt, B.E. (2012). Shifting the focus to student learning: Characteristics of effective teaching practice as identified by experienced pre-service faculty advisors. Brock Education Journal, 22(1), 93-110.

Maynes, N. \& Hatt, B. E. (2013). Hiring and supporting new teachers who focus on students' learning. Canadian Journal of Educational Administration and Policy, 144. Retrieved from https://files.eric.ed.gov/fulltext/EJ1017211.pdf

Miller, J. (2009). Teacher identity. In A. Burns \& J. Richards (Eds.), Second language teacher education. (pp. 172-181). New York, NY: Cambridge University Press.

Presbitero, A. (2016). Culture shock and reverse culture shock: the moderating role of cultural intelligence in international students' adaptation. International Journal of Intercultural Relations, 53, 28-38.

Villegas-Reimers, E. (2003). Teacher professional development: an international review of the literature. International Institute for Educational Planning. Retrieved from http://unesdoc.unesco.org/images/0013/001330/133010e.pdf

\section{Appendix A. Results from the later open-ended survey questions (qualitative measures)}




\begin{tabular}{|c|c|}
\hline \multicolumn{2}{|l|}{ Culture and Language : Certificate Holders } \\
\hline Home Country & Foreign Country \\
\hline Learning about new cultures was fun. & ...started learning the language and opening my mind \\
\hline Learned about the L1s I was teaching to & $\begin{array}{l}\text {...learned a few words and phrases to operate in the } \\
\text { community. Vendors were friendly and helpful, even } \\
\text { using non-verbal communication. }\end{array}$ \\
\hline \multicolumn{2}{|l|}{ Culture and Language : BA or Above } \\
\hline \multirow[t]{4}{*}{ Home Country } & Foreign Country \\
\hline & Tried to learn as much as possible \\
\hline & $\begin{array}{l}\text { I had to learn to be more flexible about time and } \\
\text { punctuality. Cultural values were different and not } \\
\text { everyone was operating with the same values } \\
\text { systems...it takes time to learn what those underlying } \\
\text { values are. I just learned from experience and from } \\
\text { talking to friends who were native to that culture. }\end{array}$ \\
\hline & $\begin{array}{l}\text {...made it a priority to appreciate and enjoy learning the } \\
\text { new language and culture }\end{array}$ \\
\hline
\end{tabular}

\begin{tabular}{|l|l|}
\hline Q8: Briefly describe how you responded to the challenges you faced. \\
\hline Workplace Routines: Certificate Holders & Foreign Country \\
\hline Home Country & $\begin{array}{l}\text { This was difficult, as communication (openness) about } \\
\text { what was expected or how to do things was not always } \\
\text { forthcoming. }\end{array}$ \\
\hline $\begin{array}{l}\text { The routine was rather unique since I traveled to about } \\
\text { was very new I had to keep explaining my job to the } \\
\text { other teachers each time I came }\end{array}$ & Foreign Country \\
\hline Workplace Routines: BA or Above & $\begin{array}{l}\text { Not everyone was as committed as I was...some people } \\
\text { are a bit more lax. I saw that, in general, others realized } \\
\text { this, though, so they did not hold me personally } \\
\text { responsible for lapses in communication or for problems } \\
\text { with tardiness or scheduling. }\end{array}$ \\
\hline $\begin{array}{l}\text { Home Country } \\
\text { I asked my new co-workers a lot! }\end{array}$ & $\begin{array}{l}\text { Asked questions/ read handbooks and manuals } \\
\text { Just had to buckle down and do what I was asked. It } \\
\text { training of any kind. It truly was "sink or swim". }\end{array}$ \\
\hline $\begin{array}{l}\text { colleagues and supervisors } \\
\text { collowed procedures and asked many questions to my }\end{array}$ \\
\hline
\end{tabular}




\begin{tabular}{|l|l|}
\hline \multicolumn{2}{|l|}{ Q8: Briefly describe how you responded to the challenges you faced. } \\
\hline Co-workers: Certificate Holders & Foreign Country \\
\hline Home Country & $\begin{array}{l}\text { Worked with Mongolian English teachers, but they have } \\
\text { a different idea of what it is to share information, plan } \\
\text { ahead, grade honestly, so it was a rough adjustment... }\end{array}$ \\
\hline Co-workers: BA or Above & Foreign Country \\
\hline Home Country & ...learned about the home culture of my co-workers \\
\hline $\begin{array}{l}\text { I didn't feel support from most co-workers, so I avoided } \\
\text { them. }\end{array}$ & \\
\hline
\end{tabular}

\begin{tabular}{|l|l|}
\hline Q8: Briefly describe how you responded to the challenges you faced. \\
\hline Students: Certificate Holders & Foreign Country \\
\hline Home Country & ..troubleshooted with teachers; thought back to my \\
\hline $\begin{array}{l}\text { I was very intimidated by them at first. They were all } \\
\text { quite highly educated, very high powered professionals. } \\
\text { But I came to love them. }\end{array}$ & Foreign Country \\
\hline Students: BA or Above & $\begin{array}{l}\text { Thankfully, my students (although few in number) are } \\
\text { highly motivated to learn, I only wish I had been } \\
\text { allowed more access to recruit more. }\end{array}$ \\
\hline $\begin{array}{l}\text { It was challenging to always make sure the needs of my } \\
\text { students were met, especially that as a new teacher I } \\
\text { was very eager to please. Also, explaining things and } \\
\text { answering students' questions is the most difficult at } \\
\text { the beginning (it gets much easier with time and with } \\
\text { more experience). }\end{array}$ & \\
\hline $\begin{array}{l}\text { I tried to learn as much as I could about their culture. } \\
\text { The big problem is teaching students that have no any } \\
\text { motivation to learn, the best thing is that you do your } \\
\text { best in using different approaches in teaching and } \\
\text { create games. in fact, teacher has to be patient till the } \\
\text { semester finished and then she will feel the real } \\
\text { happiness }\end{array}$ & \\
\hline
\end{tabular}




\begin{tabular}{|c|c|}
\hline \multicolumn{2}{|l|}{ Certificate Holders } \\
\hline Home Country & Foreign Country \\
\hline $\begin{array}{l}\text { Don't feel you have to know everything - there are no } \\
\text { real emergencies here. Give yourself plenty of time to } \\
\text { prep; be flexible, creative and have fun with it }\end{array}$ & $\begin{array}{l}\text { Trust your training and establish routines that remind } \\
\text { you of home. Feel free to reach out to veteran teachers } \\
\text { or staff for advice when dealing with difficult situations } \\
\text { or students. It's not easy but can be very rewarding. }\end{array}$ \\
\hline $\begin{array}{l}\text { Ask lots of questions and use this first year to really } \\
\text { develop your theories as a teacher! }\end{array}$ & $\begin{array}{l}\text { I would say, learn as much about the new culture as you } \\
\text { can before you go. Also, try to learn some vocabulary } \\
\text { and simple phrases. Engage the culture; eat what they } \\
\text { eat, try to experience everything you can, and look for } \\
\text { the gold in people. By getting out into the community, } \\
\text { you will understand your students better. Try to learn } \\
\text { your students' name quickly, along with the correct } \\
\text { pronunciation. Don't assume they understand; check for } \\
\text { understanding. Listen a lot to what they say and how } \\
\text { they say it, ask questions, and let them teach you too... } \\
\text { Relax and make it fun! }\end{array}$ \\
\hline $\begin{array}{l}\text { Be ready to be flexible with a lot, but stick to your guns } \\
\text { regarding the important stuff. Learn the cultures and } \\
\text { L1s you will be working with (and associated strengths } \\
\text { and weaknesses). For ex[ample], some cultures will } \\
\text { think everything (including grades) are negotiable as } \\
\text { long as you're talking about it, so you need to shut down } \\
\text { the conversation before it escalates and they expect you } \\
\text { to revise your data because they're complaining. Other } \\
\text { cultures/L1s need the extra encouragement with } \\
\text { speaking aloud and to build their confidence to know } \\
\text { that mistakes are okay and part of how they'll improve. } \\
\text { Learn your audience and teach to them specifically. }\end{array}$ & $\begin{array}{l}\text { Follow what you learned in training. Turns out, they } \\
\text { were right! }\end{array}$ \\
\hline \multicolumn{2}{|l|}{$\begin{array}{l}\text { If possible, go in with a network of outside support, and } \\
\text { also hold classroom "success" loosely, being willing to } \\
\text { learn and change with each situation. }\end{array}$} \\
\hline \multicolumn{2}{|l|}{ Co-workers: BA or Above } \\
\hline Home Country & Foreign Country \\
\hline $\begin{array}{l}\text { Don't get discouraged if everything seems difficult at the } \\
\text { beginning, and if things often don't go as planned. You } \\
\text { are not a bad teacher just because you can't answer all } \\
\text { the questions you get. It all gets easier with time. It } \\
\text { really, really does. }\end{array}$ & $\begin{array}{l}\text { Try to embrace the new culture and put yourself in } \\
\text { others' shoes }\end{array}$ \\
\hline Don't give up. & $\begin{array}{l}\text { First year is the toughest so if you feel like giving up, } \\
\text { give it more time and you will feel more comfortable in } \\
\text { the second year. }\end{array}$ \\
\hline $\begin{array}{l}\text { Be ready for challenges, be flexible and develop a good } \\
\text { sense of humor, seek advice from other teachers and } \\
\text { look for opportunities to sharpen your knowledge and } \\
\text { skills. }\end{array}$ & $\begin{array}{l}\text { Find a school / workplace that has a good legal team in } \\
\text { place that are used to processing paperwork for your } \\
\text { visa and work permit. This can take a lot of the pressure } \\
\text { off of you...AND in many countries, you need to find a } \\
\text { workplace that has considerable influence in the } \\
\text { community where you live. That can make things go } \\
\text { much more smoothly. Even if this means you have to }\end{array}$ \\
\hline
\end{tabular}




\begin{tabular}{|c|c|}
\hline & $\begin{array}{l}\text { take a second job to get your visa secured, it is worth it. } \\
\text { Having to worry constantly about your resident status is } \\
\text { not worth the trouble. }\end{array}$ \\
\hline $\begin{array}{l}\text { Ask for a mentor teacher and meet regularly with him } \\
\text { or her. This has been helpful every time I have had one. } \\
\text { Also, have regular meetings with your administration to } \\
\text { keep a good rapport and know what are the steps you } \\
\text { need to take for disciplinary action / classroom } \\
\text { management. Take time for students outside of the class } \\
\text { when culture / situation allows for this. This mentorship } \\
\text { role really has been the place for some of the richest } \\
\text { times for me being a teacher. }\end{array}$ & $\begin{array}{l}\text { Learn as much as you can about the local culture, which } \\
\text { includes the community and the institution where you } \\
\text { teach English }\end{array}$ \\
\hline \multirow[t]{2}{*}{$\begin{array}{l}\text {...you will learn new things in the first year while } \\
\text { teaching, try to apply what you have learned, and to be } \\
\text { fruitful, productive in your workplace. }\end{array}$} & $\begin{array}{l}\text { Stay longer than a year to get a better experience. I left } \\
\text { after a year, but I was told that you really need "to } \\
\text { survive " a year in order to become acculturated. }\end{array}$ \\
\hline & $\begin{array}{l}\text {...really try to get on the good side of your supervisor(s), } \\
\text { lead teacher(s), co-teacher(s), and fellow teachers-- } \\
\text { whomever is most responsible for you when you start. } \\
\text { Usually they are asked to support and mentor you with } \\
\text { no added compensation and may initially view you as a } \\
\text { burden (especially if you are new to their country, } \\
\text { culture, and language and you need to rely on them for } \\
\text { things outside of your teaching day). After that, patience } \\
\text { and flexibility are the most important. You could teach } \\
\text { in the same place for years and still not fully } \\
\text { understand how the culture works, and how your school } \\
\text { and your position work within that culture and the } \\
\text { expectations occurring from various people (principals, } \\
\text { supervisors, colleagues, admin, parents, and students). }\end{array}$ \\
\hline
\end{tabular}

*Some of the above quotes may have been summarized to communicate main ideas in order to make the table more condensed. These quotes were chosen because they seemed most relevant to the research questions addressed in the study. If you would like to see the quotes in their original form, please contact the authors.

\section{Copyrights}

Copyright for this article is retained by the author(s), with first publication rights granted to the Journal.

This is an open-access article distributed under the terms and conditions of the Creative Commons Attribution license (CC BY-NC-ND) (http://creativecommons.org/licenses/by-nc-nd/4.0/). 